TRANSPORTATION MODAL CHOICE FOR A HYBRID INVENTORY CONTROL PROBLEM

\author{
By \\ Atena Mahiny \\ Bachelor of Biomedical Engineering \\ Ryerson University, 2015
}

\author{
A MRP \\ Presented to Ryerson University \\ in partial fulfilment of the \\ requirement for the degree of \\ Master of Engineering \\ in the program of \\ Mechanical and Industrial Engineering
}

Toronto, Ontario, Canada, 2017

CAtena Mahiny 2017 


\section{Author's Declaration}

I hereby declare that I am the sole author of this MRP. This is a true copy of the thesis, including any required final revisions, as accepted by my examiners.

I authorize Ryerson University to lend this MRP to other institutions or individuals for the purpose of scholarly research.

I further authorize Ryerson University to reproduce this MRP by photocopying or by other means, in total or in part, at the request of other institutions or individuals for the purpose of scholarly research.

I understand that my MRP may be made electronically available to the public. 


\title{
TRANSPORTATION MODAL CHOICE FOR A HYBRID INVENTORY CONTROL PROBLEM
}

\author{
Master of Industrial Engineering, Spring 2017 \\ Atena Mahiny, Ryerson University
}

\begin{abstract}
In this report I tried to develop a model to control remanufacturing transportation cost for a reverse supply chain considering various serviceable and remanufacturable inventory stock points. While consumers traditionally dump the products at the end of their life cycle, there is an option to return them to the manufacturers for renew and reuse. As a result, manufacturers must collect products at the end of their life and control their recovery or disposal situation. Product recovery, which includes reusing, remanufacturing and recycling, requires a reverse logistic network in order to increase efficiently. This report presents the results of a simulation model for a reverse logistics network for collecting the returned cartridge toners from customers. Real data from an Australian case company was utilized to design test experiments in order to validate and evaluate the model.
\end{abstract}




\section{Acknowledgment}

I have taken efforts in this project. However, it would not have been possible without the kind support and help of many individuals.

I am highly indebted to my supervisor Dr. Hossein Zolfagharinia as well as my co-supervisor Dr. Sharareh Taghipour for their guidance and constant supervision as well as for providing necessary information regarding the project $\&$ also for their support in completing the project.

I would like to express my special thanks to my dear friend Payam Emadi and Mina Nozohouri for the giving me much support and time.

I would like to express my gratitude towards my mother and my sister for their kind co-operation and encouragement which help me in completion of this project. 


\section{Table of Contents}

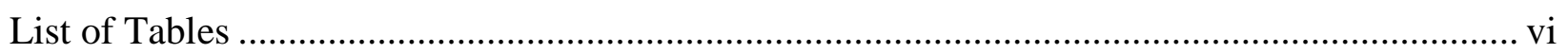

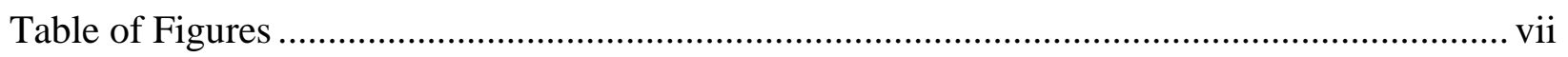

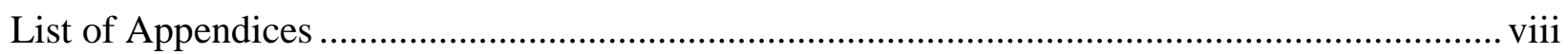

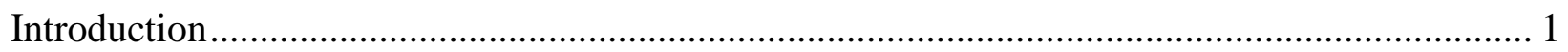

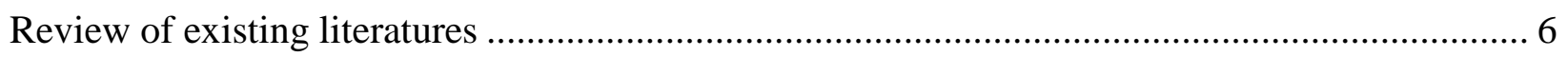

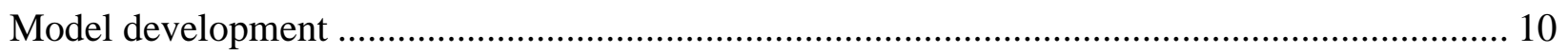

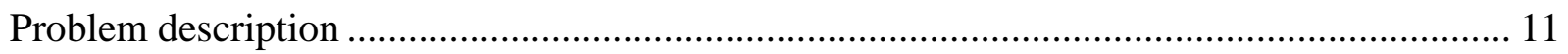

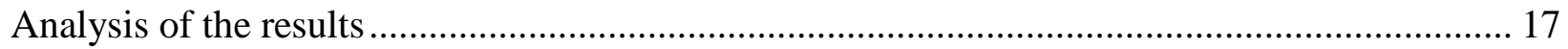

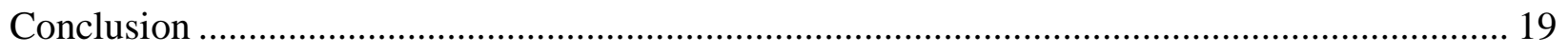

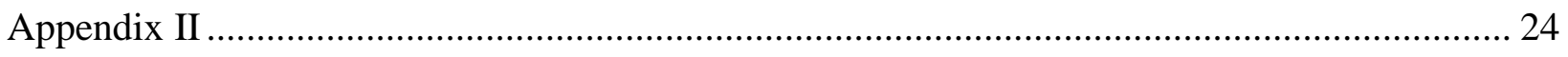

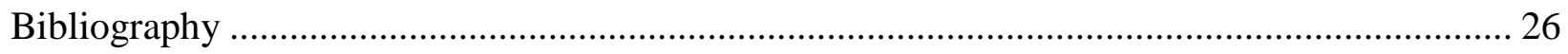




\section{List of Tables}

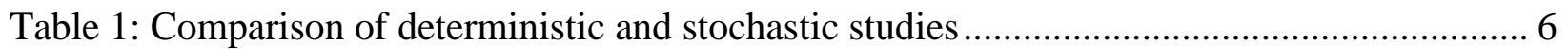

Table 2: Transportation by truck - 8, 12, 16 hours , \$1 per item in 365 days................................ 14

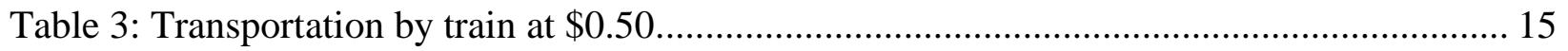

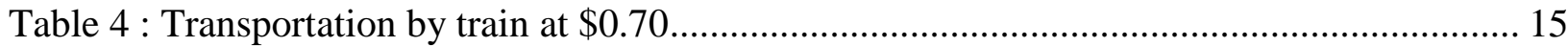

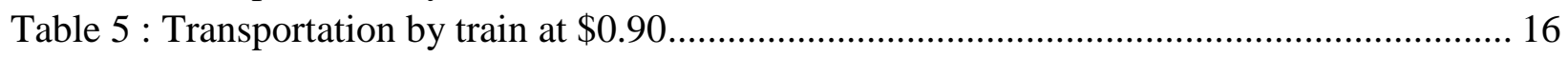

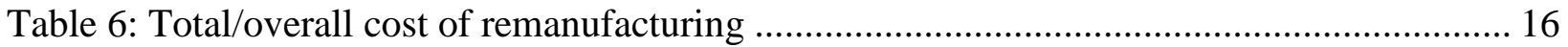




\section{Table of Figures}

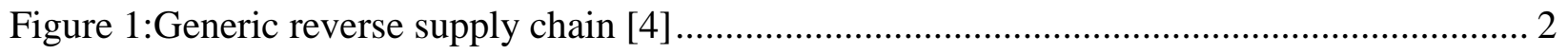

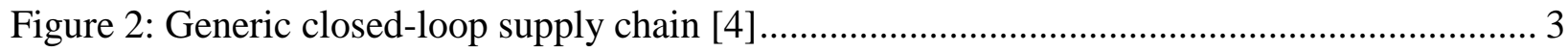

Figure 3: A framework for reverse supply chain activities [20] .......................................... 7

Figure 4:The role of transportation in reverse logistics [5] ........................................... 11

Figure 5: Total overall cost for different transportation methods .......................................... 18 


\section{List of Appendices}

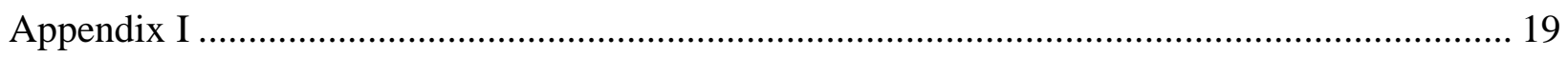

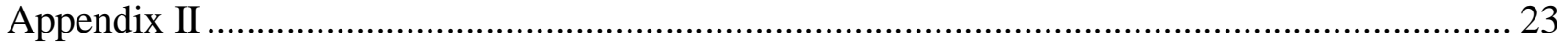




\section{Introduction}

As the world's population grows, the level of consumption of limited resources and disposal capacities has been continuously increasing. Furthermore, with the rapid technological development of new products, the desire of consumers to acquire the latest technology grows accordingly. Consequently, product recovery activities are becoming incorporated into the manufacturing process. Examples of such activities include the refurbishing, repairing, remanufacturing, recycling and cannibalization of returned products accepted by many manufacturers for the purpose of reprocessing [1].

Remanufacturing involves restoring used products (in our case returned products) through a set of processes that typically involves inspection, disassembly, reassembly and reconditioning [2]. In many cases, remanufactured products are considered "as good as new" and are used to satisfy the level of the demands for new products sold for the same price, but at a lower cost for the manufacturer [3]. Not all the returned products are in the condition of renewability; so it is not worthy to return them for remanufacturing or entering to the model that we are proposing. That is why it is of more importance to first evaluate them for their condition of dumping or reusability. Furthermore, remanufactured products alone are not enough to completely satisfy all customer demands, hence brand-new products will also be needed to be produced in the manufacturing plant or be supplied from other suppliers. In order to achieve the overall profit target and to satisfy demands, the manufacturer must ensure sufficient supply of products in the form of new and remanufactured way. 
In order to fulfill a customer request a supply chain (SC) involves with various parties, directly or indirectly [4]. The reverse supply chain (RSC) also known as reverse logistic (RL) consists of a series of activities required to collect a used product from a consumer and reprocess it to either recover its leftover market value or dispose of it [4]. At least three parties are required for the implementation of any reverse supply chain: 1) Collection centers where consumers return used products, 2) Recovery facilities where reprocessing is performed, and 3) Demand centers where customers buy reprocessed products. Figure 1 displays a generic reverse supply chain:

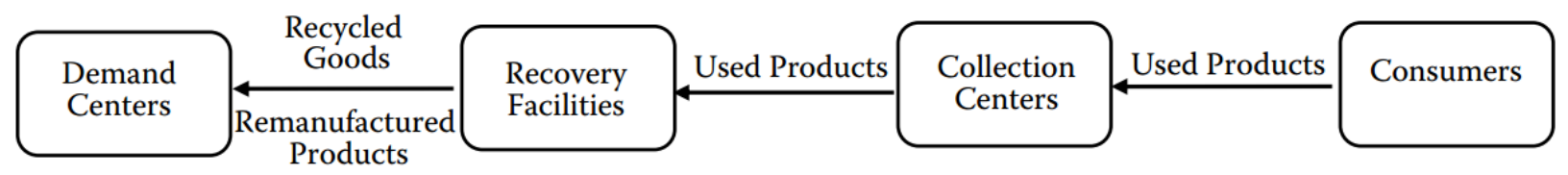

Figure 1:Generic reverse supply chain [4] 
The combination of forward and reverse supply chains is called a closed-loop supply chain [4]. A generic closed-loop supply chain is shown in Figure 2.

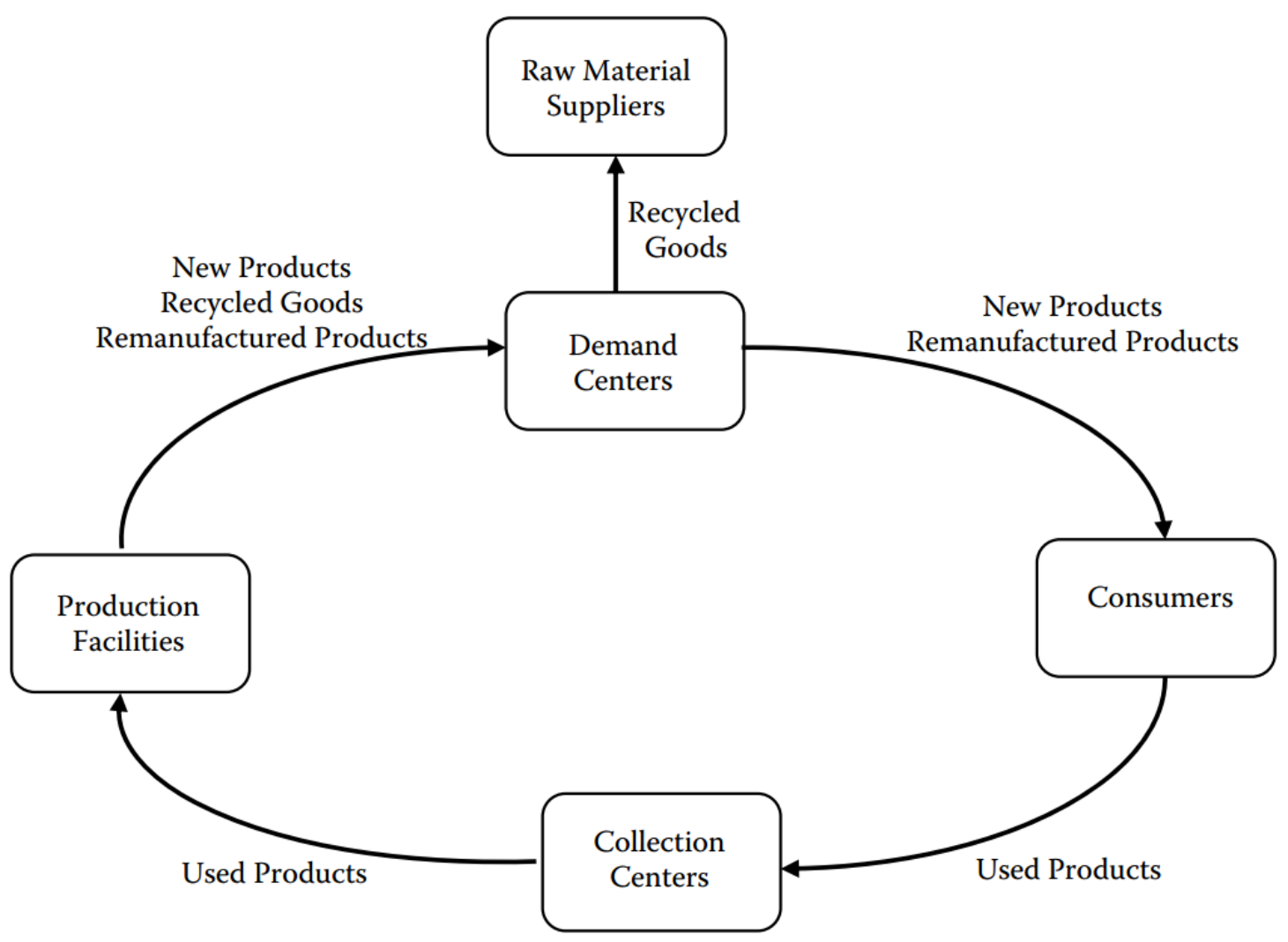

Figure 2: Generic closed-loop supply chain [4]

A well-managed RL system can not only provide important cost savings for inventory holding, transportation, attainment, recovery and disposal, but also help in customer retention which is very important in order to remain competitive.

The role of transportation in RL is essential as it plays two important roles. First, inbound and outbound transportation are the most essential portion of RL operations. Without suitable 
transportation of returned goods from the point of consumption to the processing service centers and then shipment of the remanufactured products to new customers, RL operations cannot be sustained. Second, transportation costs play an important role in the viability of the entire RL system. Transportation costs are influenced by the flow of items in supply chains. If the transportation cost is excessive, the profitability of RL systems will be severely reduced. This is especially important, given that the profit margins for many remanufactured items are usually small [5].

Managers of a supply chain have two main goals: 1) To keep the level of inventory in the supply chain as low as possible, reducing inventory costs while balancing these costs against ordering costs and 2) To move the products in their continually changing form or location and to manage the physical distribution to the final consumer at different locations, or back into remanufacturing or recycling as fast as possible [6].

In this Paper, a reverse logistics network for retuned toner cartridges collection in an Australian company is presented, including the corresponding simulation model. The aim of the paper is to expand the research on the development of a realistic two-stock inventory control model and provide a flexible model to address some of the aforementioned problems associated with reverse logistics networks. A two-stock control model can be described as a model with separate serviceable and remanufacturable inventory stock points with stochastically expressed market demand and product return [7].The serviceable inventory stock point is where the final product is stored and the remanufacturable stock point carries returned items suitable for remanufacturing.

The objective of this study is to identify transportation factors associated with an RL system. The transportation subsystems represent various components on overall transportation system. Subsystems include transportation costs, schedules, routes, and various transportation 
technologies. A reverse logistics network was designed to establish transfer stations, drop-off points and a disassembly plant using Arena15.0 simulation package. 


\section{Review of existing literatures}

For the last decade, increasing concerns over environmental degradation and increased opportunities for cost savings or revenues from returned products prompted some researchers to formulate more effective reverse logistics strategies within the closed-loop supply chain network.

Reserve supply chains can be classified into two group; Deterministic and stochastic. The Table 1 organizes various research efforts performed into groups of stochastic and deterministic with an emphasis on stocking points used.

Table 1: Comparison of deterministic and stochastic studies

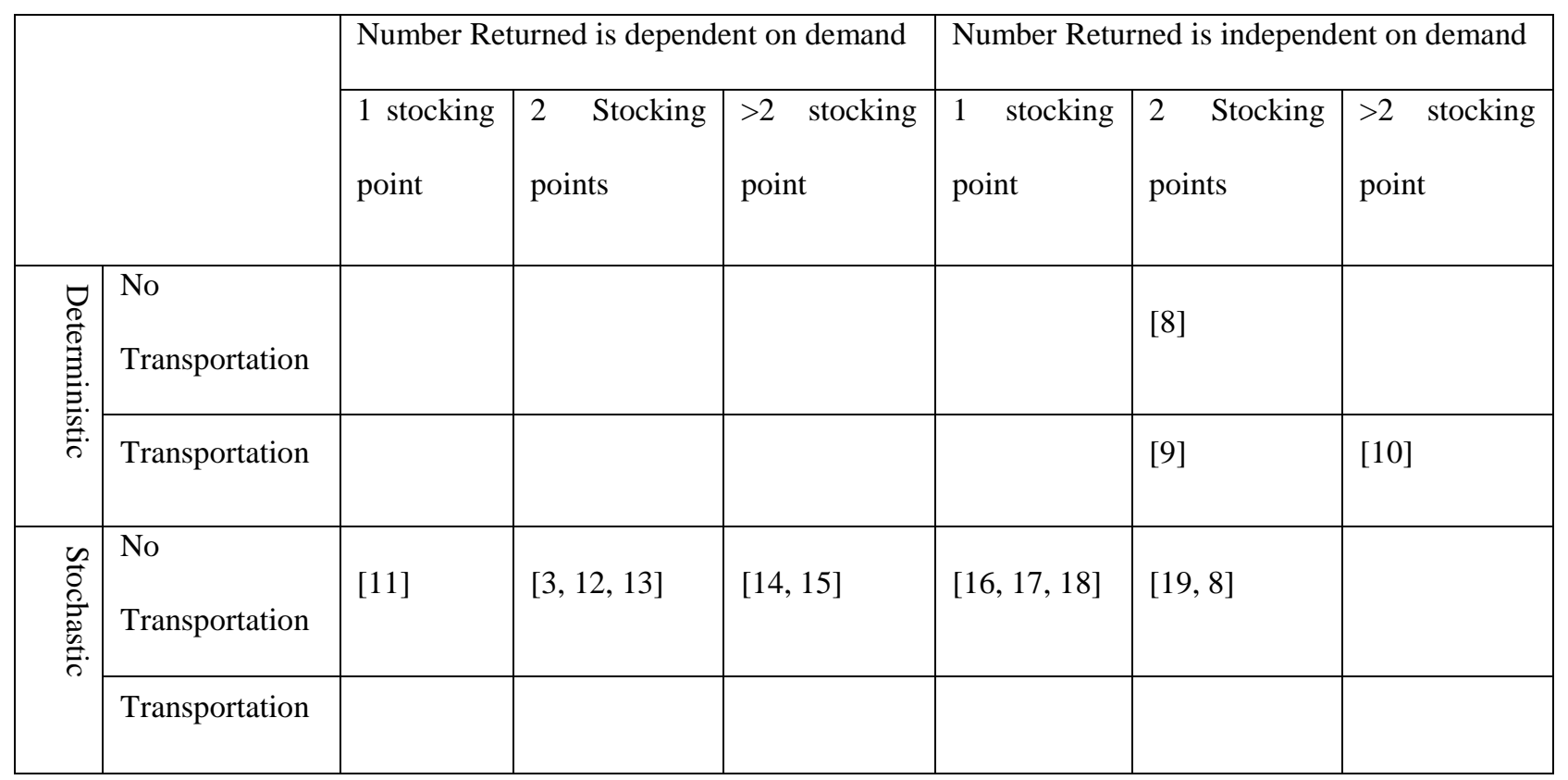

Studies in the literature associated with RL have been conducted on different aspects such as network design, return forecasting, economic and environmental performance, lot sizing, vehicle routing, etc. 
Kannan et al. presented a mixed integer linear model for a carbon footprint based on Reverse Logistics Network Design (RLND) [20]. The developed model was aimed to minimize the costs involved in the RLND, and it considered the carbon footprint involved both in transportation and reverse logistics operations costs. The study employed reverse logistics activities to recover used products, hence including the location/transportation decision problem as seen in Figure 3. As a result, the authors developed a model useful for supply chain managers to make decisions by incorporating environmental emissions into their costs [20].

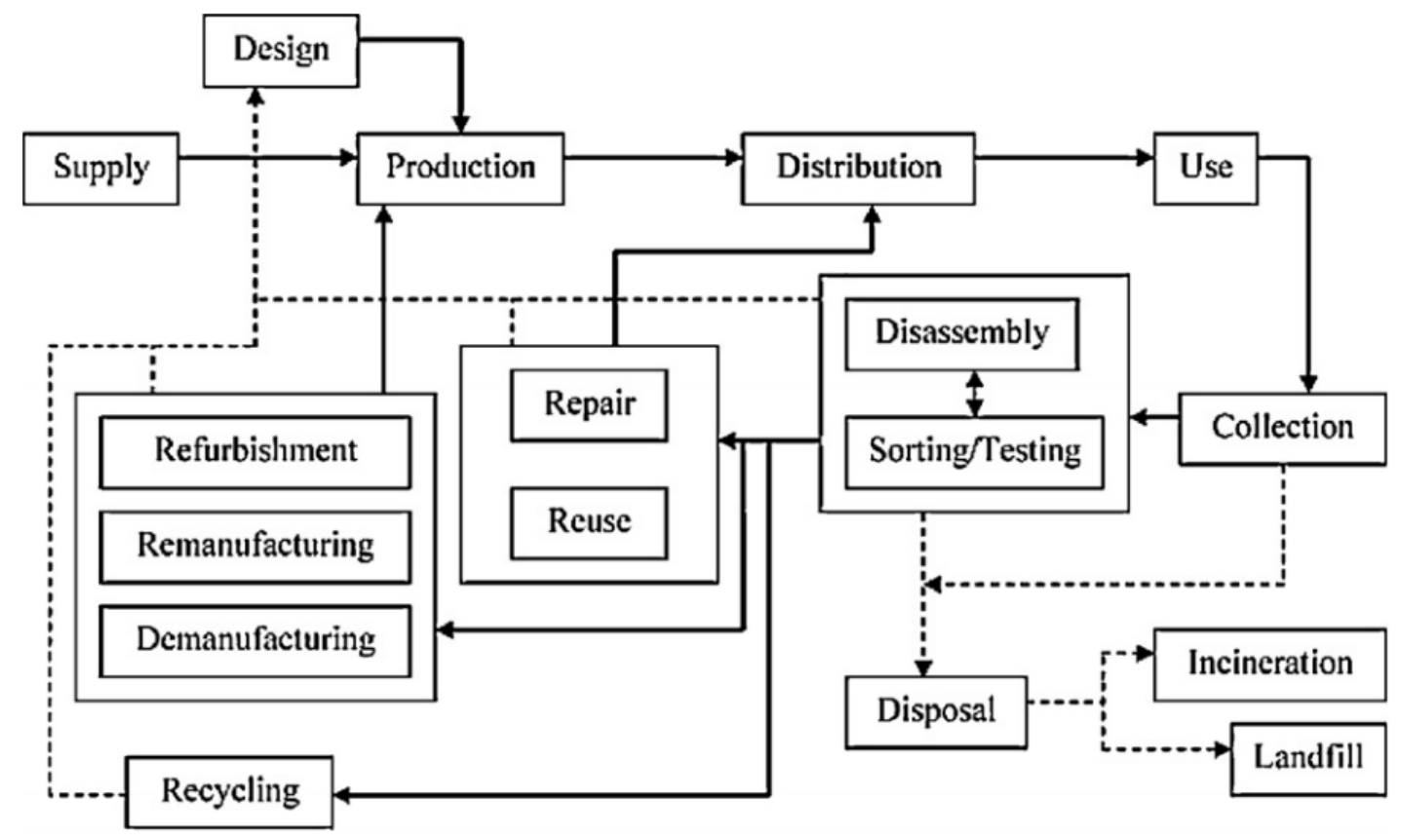

Figure 3: A framework for reverse supply chain activities [20]

Ahiska and King performed a study on a two supply chain mode, manufacturing and remanufacturing with considering two stocking points and one lead time. They used discretetime Markov decision process (MDP) and a stochastic model. MDP provides a mathematical 
framework for modeling and decision making in situations where outcomes are partially random and partially under the control. The study investigated the optimal inventory policies over the life cycle of a remanufacturable products. By using the long-run optimal policies found through Markov decision analysis, the optimal or near-optimal policy characterizations with practical structure were determined for every life cycle stage under several setup cost configurations. The effects of changes in the demand and return rates on the optimal inventory policies were investigated through these policies.

The study determined that the appropriate policy structures over the product life cycle depend on the setup cost structure of the system [13]. The optimal parameter values of the inventory policies were determined to be sensitive to changes in the demand and return rates and the cost of an inventory policy was sensitive to the changes in its parameters' values [13]. Therefore, it was recommended to revise the inventory policies over the product life cycle anytime a change in the rates occurs [13].

Fonseca et al. presented a comprehensive model for RL planning in which they considered many real-world features such as the existence of multi-levels, multi-commodities, choices of technology, and uncertainties associated with transportation costs and waste generation [21]. Moreover, they presented a two-stage stochastic dual-objective mixed-integer programming formulation in which strategic decisions were considered in the first stage and tactical and operational decisions in the second. The two objectives considered are the total cost and the total obnoxious effect. The results obtained were promising. It was determined that for instances of a realistic size, the model presented could be approached with a general solver [21]. Conversely, the study did not present sophisticated methodologies for scenario generation/reduction. This 
may lead to instances with a significant number of scenarios, which, in turn may justify specially tailored methodologies for tackling the problem.

Chen \& Abrishami (2014) presented a mixed integer programming model for production planning involving returned product disassembly, core remanufacturing, and new part manufacturing [22]. They used a hybrid manufacturing-remanufacturing system (HMRS) which shares a common resource as the new and returned products with the assumption of known demands for the remanufactured parts. They investigated associated costs which come with system setup, disassembling, and inventory of the returned products as well as costs to obtain or purchase the returned products and to retrieve the parts for remanufacturing. A mixed integer linear programming (MILP) was developed to obtain optimal solution of the considered problem. To efficiently solve the MILP model, a solution procedure based on Lagrangian decomposition was used so that the original model can be solved through solving a set of much smaller subproblems. The model and solution procedure were tested using several numerical examples and the results show that the proposed solution procedure can reach optimal or very close to optimal solutions in short computational time [22]. 


\section{Model development}

The very first step in working with simulation software is identifying appropriate conceptual model by which the reverse logistics infrastructure can be approached properly. In order to designing a logistics network structure several factors should be considered. In this project some of effective factors are including but not limited to "Number of customers", "Quantity of returned used toners", "Number and Location of Disassembly Center", "Collection Points and Distance between them", "Cost of Purchase, Inventory Holding, Remanufacturing and Transportation" and "Product characteristics". To guarantee the effectiveness of a system costwise these factors should be chain-linked together and work accordingly.

In this paper I tried to use an existing collection structure of Australian Toner Cartridge Company as benchmark in reverse logistic network [23]. It simulates the collection and transportation of Used Toners from users to the remanufacturing plant. It also includes one collection point and one remanufacturing plant with a centralized disassembly center with high capacity for product disassembly. 


\section{Problem description}

In this report, the main target was to reduce and control overall cost of remanufacturing by simulating in Arena. In order to reach to an optimal result, the simulation model was created based on the system description with the capability of parameters changing option. A simulation method was also used by Hellström and Johansson to investigate different control policies for managing the transportation of returnable products in a closed-loop supply chain [25]. By applying multiple performance criteria in evaluating system behavior the effectiveness of a simulation model can be increased cost- and time-wise. It can also be particularly more useful when system complexity is intensified by shifting from deterministic to stochastic modeling [7].

Figure 4Error! Reference source not found.; describe the summery of the simulation model

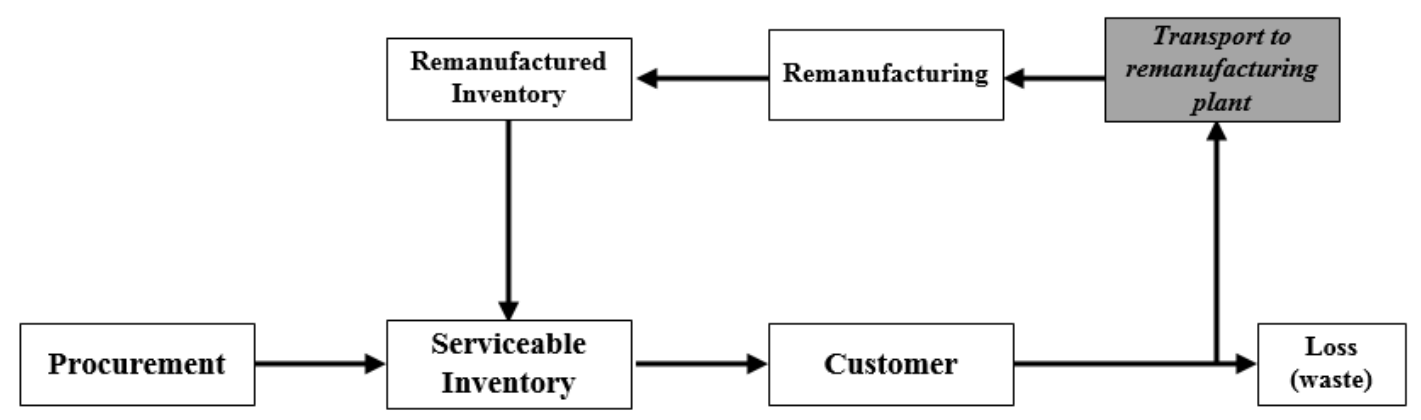

Figure 4: The role of transportation in reverse logistics [5]

Step 1: Customer comes to store

Step 2: Demand definition - Determining the demand, when customer arrives

Step 3: Check the inventory position - Company first checks their serviceable inventory (remanufactured used item) to find out if there is enough toner to fulfill the demand. If not 
(False) the company will lose the customer or else, it has to purchase new toner from supplier for higher price which is not an available option for us, hence Customer lost.

Once the inventory position is planned, the order is placed. Therefore, we have either "on-hand" or "on-way" inventory. The goal is to sell the remanufactured toners, because it has more benefit both financially and economically.

Definitely, company's intention is not to lose any customer, so it seeks to accommodate the customer needs with enough serviceable inventory.

Step 4: whenever customer orders/picks up new toner, he will either return the used toner to the collection center, or dispose it if it is not re-usable anymore.

Step 5: Carrier Company will pick up the retuned items and ship them to remanufacturing plant. The transportation cost may vary for each shipping mode.

Transportation cost with the assignment of: Total Transportation Cost + (the rate for the transportation, 1unit for truck and $0.5,0.7$ or 0.9 unit for train).

Step 6: In the remanufacturing plant, the returned product will get disassembled, checked, cleaned, refurbished and if needed some parts may be replaced. Finally, the parts will be reassembled again. Moreover, the restored parts will be tested to be justified as a new one. The "Delay" type applied in the modeling is "triangular", and the unit is "hour" and "day" for "Truck" and "Train" respectively.

Step 7: Product will be shipped back to the serviceable inventory and is ready to be sold to customers.

The returned items have to be categorized in the collection center based on their capability of renewability. The waste cartridges should be segregated and batched separately before transporting to the disassembly center. 
The main consideration is reducing the duration of the whole process, from the collection point to serviceable inventory, because if remanufacturing inventory drops down, the company has to purchase or supply new toners to customers, which will cost more. For the integration of the disassembly activity into the system, location is the main concept. This concept represents a scenario, where the centralized disassembly center is located close to the collection point.

In this section, I will deeply discuss and assess about modes of transportation, truck and train. The mode of transportation effects the transportation costs. Literature reviews reveal that transportation by truck is a preferred mode, time-wise [24]. In this scenario, the number of used trucks or trains and the distance between collection point and remanufacturing plant are indefinite. The demand depends on the time, which differs over the year and the number of returned items.

Certainly, simulation is a solution in which the transportation costs can be determined and minimized. The speed of the carriers is at random speed due to various traffic conditions. The type of trucks and trains and their container sizes in the simulation model are standardized. A real search in transporting companies and their service prices shows that in average transporting by train can be $50 \%-90 \%$ less expensive than a truck, but truck is a faster mode. So the travel time also should be interfered in the simulation which is considered as triangular distribution based on the data. The assumption was made that each truck will get to the plant in the following times: 8, 12 and 16 hours versus the train, which can take up to 3, 5, and 7 days.

With this assumption, I ran the simulation and decided to choose one unit for truck and three different units for train. So Truck is $\$ 1$ per item and train, $\$ 0.5, \$ 0.7$, and $\$ 0.9$. 
Several iterations in the data input ranging from 0.5 to 0.9 revealed that 0.7 can be an optimum selection for data entry. The simulation data in Tables 2,3,4, and 5 are presenting the results for 1 year (365 days) period with a working schedule of 24/7.

The results of the simulation for transportation cost and time are shown below:

Table 2: Transportation by truck - 8, 12, 16 hours, \$1 per item in 365 days

\begin{tabular}{|c|c|c|c|c|}
\hline Replication & $\begin{array}{c}\text { Total } \\
\text { Purchasing } \\
\text { Cost }\end{array}$ & $\begin{array}{c}\text { Remanufacturing } \\
\text { Cost }\end{array}$ & $\begin{array}{c}\text { Inventory } \\
\text { Holding Cost }\end{array}$ & $\begin{array}{c}\text { Total } \\
\text { Transportation } \\
\text { Cost }\end{array}$ \\
\hline \hline $\mathbf{1}$ & 1722.6 & 3391.7 & 73.43 & 1246.9 \\
\hline $\mathbf{2}$ & 1520.6 & 3387.5 & 69.8 & 1235.4 \\
\hline $\mathbf{3}$ & 1832.5 & 3454.4 & 72.5 & 1320.5 \\
\hline $\mathbf{4}$ & 1810 & 3327.5 & 69.44 & 1258.9 \\
\hline $\mathbf{5}$ & 1852 & 3350.6 & 72.28 & 1264.3 \\
\hline $\mathbf{6}$ & 1733.2 & 3275 & 74.63 & 1378.4 \\
\hline $\mathbf{7}$ & 1801.6 & 3227.4 & 76.5 & 1316.6 \\
\hline $\mathbf{8}$ & 1721.4 & 3261 & 74.86 & 1308.2 \\
\hline $\mathbf{9}$ & 1792 & 3375.3 & 73.8 & 1294.3 \\
\hline $\mathbf{1 0}$ & 1810.6 & 3431.6 & 73.2 & 1278.5 \\
\hline Total(Avg) & $\mathbf{1 7 5 9 . 6 5}$ & $\mathbf{3 3 4 8 . 2}$ & $\mathbf{7 3 . 0 4 4}$ & $\mathbf{1 2 9 0 . 2}$ \\
\hline
\end{tabular}


Table 3: Transportation by train at $\$ 0.50$

\begin{tabular}{|c|c|c|c|c|}
\hline Replication & $\begin{array}{c}\text { Total } \\
\text { Purchasing } \\
\text { Cost }\end{array}$ & $\begin{array}{c}\text { Remanufacturing } \\
\text { Cost }\end{array}$ & $\begin{array}{c}\text { Inventory } \\
\text { Holing Cost }\end{array}$ & $\begin{array}{c}\text { Transportation } \\
\text { Cost }\end{array}$ \\
\hline \hline $\mathbf{1}$ & 1892.6 & 3395.3 & 72.71 & 802.5 \\
\hline $\mathbf{2}$ & 1862 & 3456.3 & 76.7 & 735.2 \\
\hline $\mathbf{3}$ & 2200.7 & 3306.8 & 75.799 & 756.3 \\
\hline $\mathbf{4}$ & 2247.6 & 3282.8 & 77.213 & 722.73 \\
\hline $\mathbf{5}$ & 1936 & 3480.9 & 76.617 & 764.3 \\
\hline $\mathbf{6}$ & 1893.6 & 3445.6 & 74.091 & 752.5 \\
\hline $\mathbf{7}$ & 1935.8 & 3366.2 & 78.546 & 783.68 \\
\hline $\mathbf{8}$ & 1954.5 & 3383 & 73.275 & 823.3 \\
\hline $\mathbf{9}$ & 2106.2 & 3471.2 & 70.845 & 726.86 \\
\hline $\mathbf{1 0}$ & 2066.3 & 3227.3 & 75.556 & 765.23 \\
\hline Total (Avg) & $\mathbf{2 0 0 9 . 5 3}$ & $\mathbf{3 3 8 1 . 5 4}$ & $\mathbf{7 5 . 1 3 5 2}$ & $\mathbf{7 6 3 . 2 6}$ \\
\hline
\end{tabular}

Table 4 : Transportation by train at $\$ 0.70$

\begin{tabular}{|c|c|c|c|c|}
\hline Replication & $\begin{array}{c}\text { Total } \\
\text { Purchasing } \\
\text { Cost }\end{array}$ & $\begin{array}{c}\text { Remanufacturing } \\
\text { Cost }\end{array}$ & $\begin{array}{c}\text { Inventory } \\
\text { Holding Cost }\end{array}$ & $\begin{array}{c}\text { Transportation } \\
\text { Cost Val }\end{array}$ \\
\hline \hline $\mathbf{1}$ & 1892.6 & 3395.3 & 72.71 & 1113.1 \\
\hline $\mathbf{2}$ & 1862 & 3456.3 & 76.7 & 1108.7 \\
\hline $\mathbf{3}$ & 2200.7 & 3306.8 & 75.8 & 1142.3 \\
\hline $\mathbf{4}$ & 2247.6 & 3282.9 & 77.213 & 1150.3 \\
\hline $\mathbf{5}$ & 1936 & 3480.9 & 76.617 & 1140.3 \\
\hline $\mathbf{6}$ & 1893.6 & 3445.6 & 74.09 & 1122.6 \\
\hline $\mathbf{7}$ & 1935.8 & 3366.2 & 78.546 & 1108.9 \\
\hline $\mathbf{8}$ & 1954.5 & 3383 & 73.275 & 1099.3 \\
\hline $\mathbf{9}$ & 2106.2 & 3471.2 & 70.845 & 1156.9 \\
\hline $\mathbf{1 0}$ & 2066.3 & 3227.3 & 75.556 & 1090.3 \\
\hline Total (Avg) & $\mathbf{2 0 0 9 . 5 3}$ & $\mathbf{3 3 8 1 . 5 5}$ & $\mathbf{7 5 . 1 3 5 2}$ & $\mathbf{1 1 2 3 . 2 7}$ \\
\hline
\end{tabular}


Table 5 : Transportation by train at $\$ 0.90$

\begin{tabular}{|c|c|c|c|c|}
\hline Replication & $\begin{array}{c}\text { Total } \\
\text { Purchasing } \\
\text { Cost }\end{array}$ & $\begin{array}{c}\text { Remanufacturin } \\
\text { g Cost }\end{array}$ & $\begin{array}{c}\text { Total } \\
\text { Inventory } \\
\text { Holding Cost }\end{array}$ & $\begin{array}{c}\text { Transportation } \\
\text { Cost }\end{array}$ \\
\hline \hline $\mathbf{1}$ & 1892.6 & 3395.3 & 72.71 & 1251 \\
\hline $\mathbf{2}$ & 1862 & 3456.3 & 76.72 & 1246 \\
\hline $\mathbf{3}$ & 2200.7 & 3306.8 & 75.79 & 1283.9 \\
\hline $\mathbf{4}$ & 2247.6 & 3282.9 & 77.21 & 1292.9 \\
\hline $\mathbf{5}$ & 1936 & 3480.9 & 76.62 & 1281.6 \\
\hline $\mathbf{6}$ & 1893.6 & 3445.6 & 74.09 & 1261.7 \\
\hline $\mathbf{7}$ & 1935.8 & 3366.2 & 78.55 & 1246.3 \\
\hline $\mathbf{8}$ & 1954.5 & 3383 & 73.27 & 1235.4 \\
\hline $\mathbf{9}$ & 2106.2 & 3471.2 & 70.84 & 1300 \\
\hline $\mathbf{1 0}$ & 2066.3 & 3227.3 & 75.56 & 1225.3 \\
\hline Total(Avg) & $\mathbf{2 0 0 9 . 5 3}$ & $\mathbf{3 3 8 1 . 5 5}$ & $\mathbf{7 5 . 1 3 4 3}$ & $\mathbf{1 2 6 2 . 4 1}$ \\
\hline
\end{tabular}

For the overall cost, inventory value was multiplied by 3 since the inventory cost per item is $\$ 3$ according to the provided data.

Table 6: total/overall cost of remanufacturing

\begin{tabular}{|c|c|c|c|c|c|}
\hline Method & $\begin{array}{c}\text { Total } \\
\text { Purchasing } \\
\text { Cost }\end{array}$ & $\begin{array}{c}\text { Remanufacturing } \\
\text { Cost }\end{array}$ & $\begin{array}{c}\text { Inventory } \\
\text { Holding } \\
\text { Cost }\end{array}$ & $\begin{array}{c}\text { Total } \\
\text { Transportation } \\
\text { Cost }\end{array}$ & Total Cost \\
\hline \hline Truck & 1759.65 & 3348.2 & 219.132 & 1290.2 & $\mathbf{6 6 1 7 . 1 8 2}$ \\
\hline Train 0.5 & 2009.53 & 3381.54 & 225.4056 & 763.26 & $\mathbf{6 3 7 9 . 7 3 5 6}$ \\
\hline Train 0.7 & 2009.53 & 3381.55 & 225.4056 & 1123.27 & $\mathbf{6 7 3 9 . 7 5 5 6}$ \\
\hline Train 0.9 & 2009.53 & 3381.55 & 225.4029 & 1262.41 & $\mathbf{6 8 7 8 . 8 9 2 9}$ \\
\hline
\end{tabular}




\section{Analysis of the results}

The developed simulation model permits user to test different transportation strategies by changing the relationship between sub-models.

According to the simulation results, the transportation cost for taking the goods to the disassembly plant lies within the interval $\$ 763.26$ to $\$ 1385.64$ per year, based on the collection strategy provided in this paper. The lowest value of $\$ 705.823$, was derived by using the train that the carrier company will charge $\$ 0.5$ per item. The highest value, $\$ 1385.64$ was obtained by using a truck to pick up the items from the collectors and returning the trucks empty to where they came from.

The purpose of the project was to find the fastest and most economical method of transportation of remanufacturing goods to make them available in the serviceable inventory at earliest time. Since the main goal is to provide the remanufactured items at shortest possible time intervals rather than purchasing the new ones from supplier, the remanufacturer will save more money by expediting the whole process.

The mean average calculated, using the simulation model for each mode was presented and it suggests that the total overall cost per year for remanufacturing from the consumer to the remanufacturing plant for the train (which charges $\$ 0.5$ per item) is $\$ 6379.73$. However, giving priority to time, the simulation shows that transporting with truck in less than one day is $\$ 6617.182$ per year with total difference of $\$ 237.45$.

Figure 5 shows that the train with rate of $\$ 0.50$ is the best option but the company should keep in mind where the rate is higher, they should choose truck as their mode of transportation. The simulation file (Appendix II) is available for the company to work with. Managers can change 
the data based on the current market rate and run the analysis to decide which mode is beneficial for them. Finally, it is obvious that the transportation mode is one of the factors that has the biggest impact on overall cost.

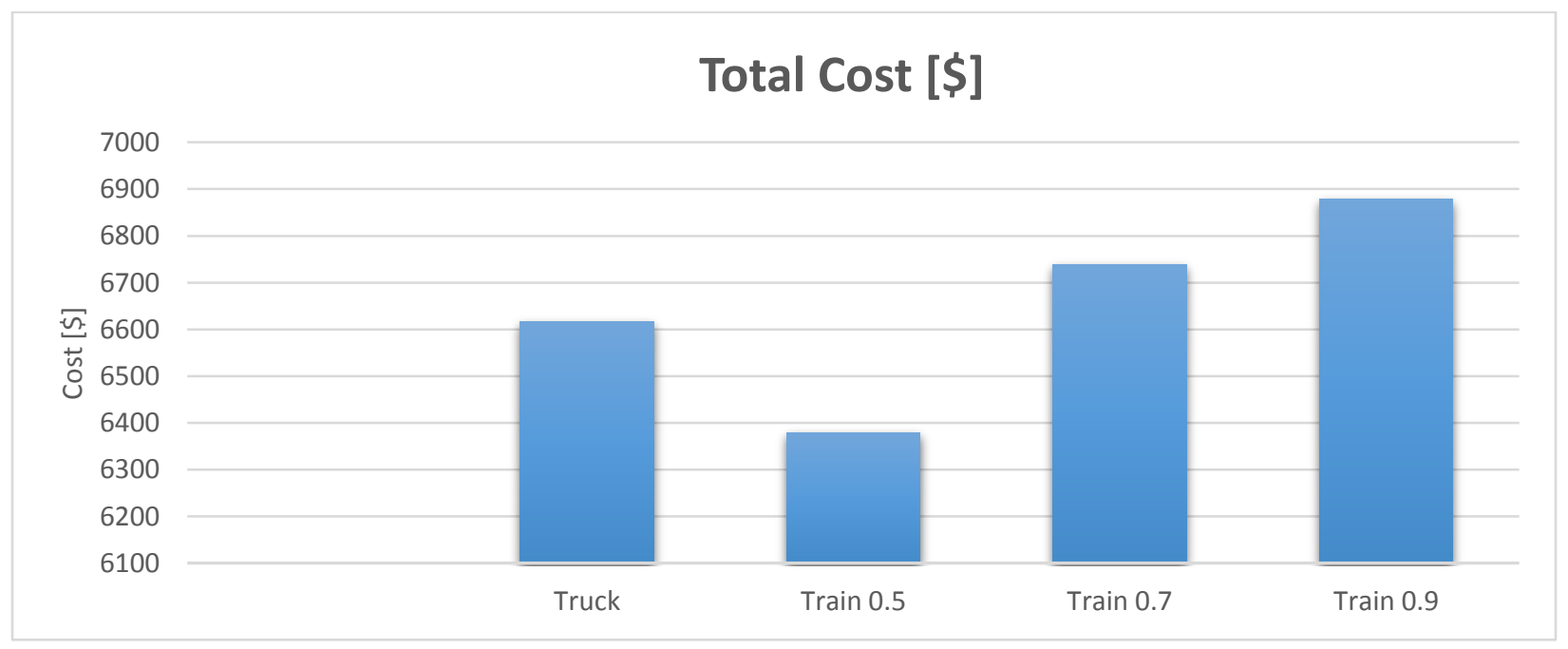

Figure 5: Total overall cost for different transportation methods 


\section{Conclusion}

The principle of reverse logistics has provided the basis for this report. It which investigates the remanufacturing system for used toner cartridges collected from consumers, and the transportation to the remanufacturing plant. The simulation model, used in this report, allows the user to analyze the future performance of the network and to understand the complex relationship between the sub components involved. Although the simulation model was tested by using end of life good collection process, it is equally useful for simulating the collection of other end of life products. The results of the simulation suggests that the model outputs the collection cost in stochastic way. The main significance of the results is in the understanding of how the system performs by carrying out various assessments with different scenarios, and by analyzing which factors are most important for further analysis. In this report, we focused on the transportation from collecting department to the manufacturing plant.

For the future work, adding the transportation cost from remanufacturing plant to serviceable inventory can be considered. 


\title{
Appendix I
}

\author{
ARENA Simulation Results \\ Atena - License: STUDENT
}

Summary for Replication 1 of 10

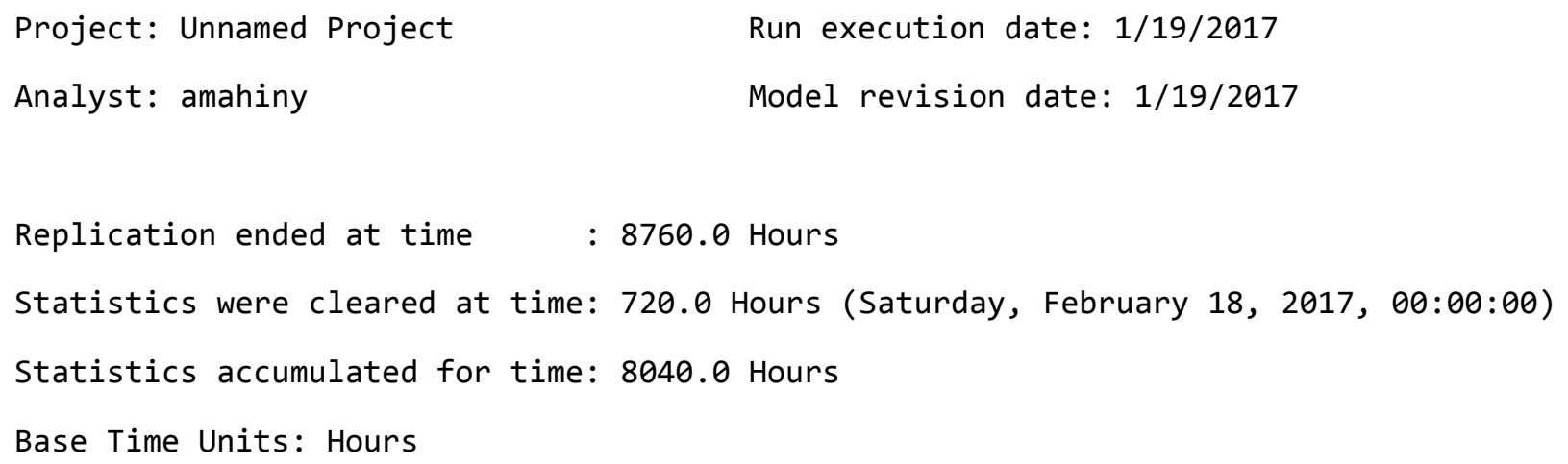

TALLY VARIABLES

Identifier Average Half Width Minimum Maximum Observations

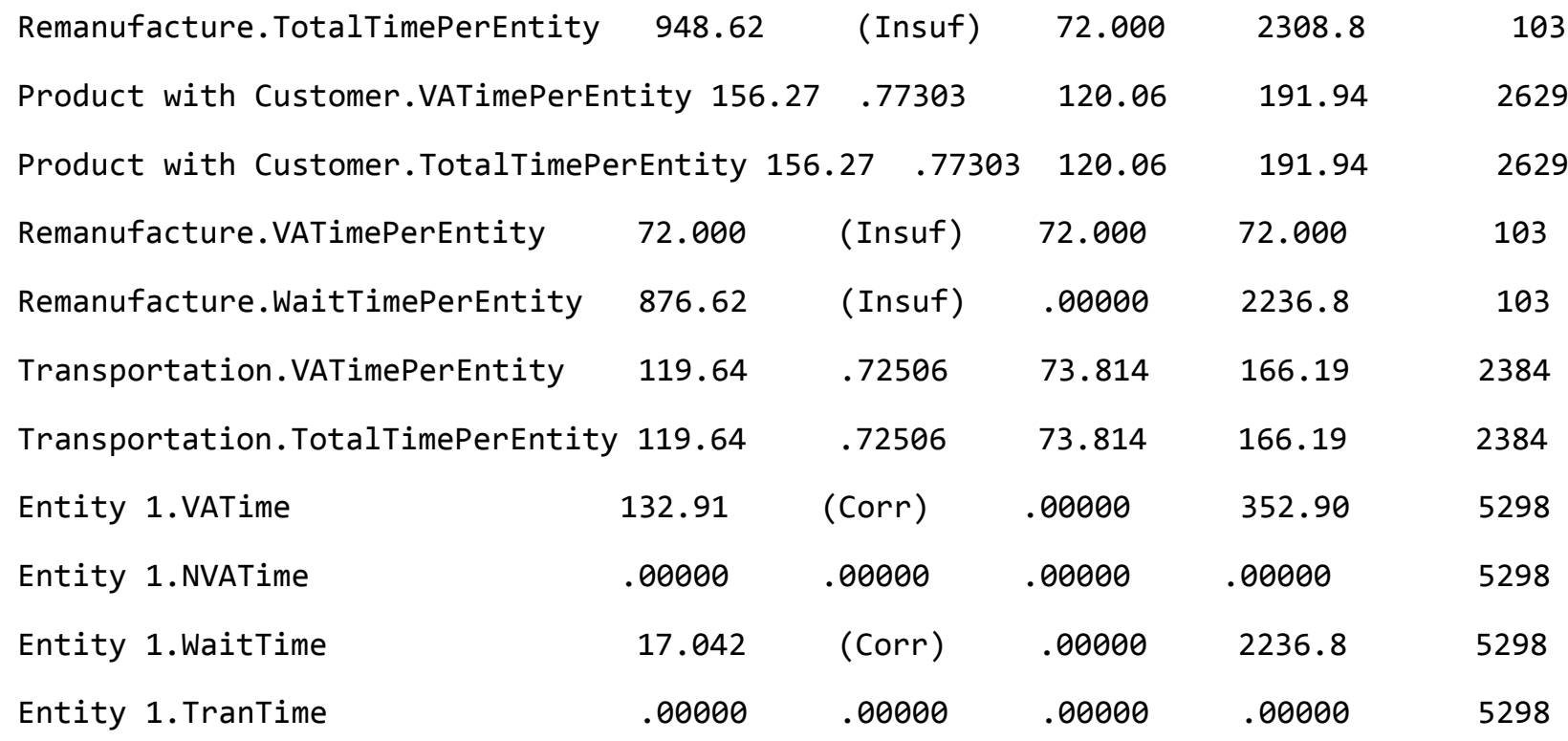




$\begin{array}{llllll}\text { Entity 1.0therTime } & .00000 & .00000 & .00000 & .00000 & 5298 \\ \text { Entity 1.TotalTime } & 149.95 & 6.7926 & .00000 & 2308.8 & 5298 \\ \text { Remanufacture.Queue.WaitingTime } & 875.28 & \text { (Insuf) } & .00000 & 2236.8 & 103\end{array}$

DISCRETE-CHANGE VARIABLES

Identifier Average Half Width Minimum Maximum Final Value

\begin{tabular}{|c|c|c|c|c|c|}
\hline TotalCustomers Value & 1572.2 & (Corr) & 221.00 & 2875.0 & 2875.0 \\
\hline MetDemand Value & 1572.2 & (Corr) & 221.00 & 2875.0 & 2875.0 \\
\hline TotalPurchasingCost Value & 1892.6 & (Insuf) & 720.00 & 3120.0 & 3120.0 \\
\hline BatchSize Value & 10.000 & (Insuf) & 10.000 & 10.000 & 10.000 \\
\hline LostProfit Value & .00000 & (Insuf) & .00000 & .00000 & .00000 \\
\hline ReorderPoint Value & 40.000 & (Insuf) & 40.000 & 40.000 & 40.000 \\
\hline HoldingCost Value & 1.0000 & (Insuf) & 1.0000 & 1.0000 & 1.0000 \\
\hline Demand Value & 1.0000 & (Insuf) & 1.0000 & 1.0000 & 1.0000 \\
\hline Remanufacturable Value & 13.474 & 2.8217 & .00000 & 93.000 & 5.0000 \\
\hline CustomerCost Value & 10.000 & (Insuf) & 10.000 & 10.000 & 10.000 \\
\hline RemanufacturingCost Value & 3.0000 & (Insuf) & 3.0000 & 3.0000 & 3.0000 \\
\hline RemanufactureCost Value & 3395.3 & (Insuf) & 240.00 & 6420.0 & 6420.0 \\
\hline PurchasingCost Value & 4.0000 & (Insuf) & 4.0000 & 4.0000 & 4.0000 \\
\hline LostCustomer Value & .00000 & (Insuf) & .00000 & .00000 & .00000 \\
\hline AmountLost Value & .00000 & (Insuf) & .00000 & .00000 & .00000 \\
\hline Total Transportation Cost Value & 1251.0 & (Corr) & 162.10 & 2305.0 & 2305.0 \\
\hline TargetStock Value & 400.00 & (Insuf) & 400.00 & 400.00 & 400.00 \\
\hline Remanufactured value & 1131.7 & (Insuf) & 80.000 & 2140.0 & 2140.0 \\
\hline Purchased Value & 473.15 & (Insuf) & 180.00 & 780.00 & 780.00 \\
\hline Revenue Value & $1.5319 \mathrm{E}+07$ & (Corr) & $2.4310 \mathrm{E}+05$ & $4.1314 \mathrm{E}+07$ & $4.1314 \mathrm{E}+07$ \\
\hline NoReturnedToRemanu Value & 20.000 & (Insuf) & 20.000 & 20.000 & 20.000 \\
\hline Inventory Value & 72.710 & 4.9792 & 18.000 & 119.00 & 85.000 \\
\hline Profit Value & 5.0000 & (Insuf) & 5.0000 & 5.0000 & 5.0000 \\
\hline
\end{tabular}




\begin{tabular}{|c|c|c|c|c|c|}
\hline Total Demand & 1.0000 & (Insuf) & 1.0000 & 1.0000 & 1.0000 \\
\hline Returned Items & 13.474 & 2.8217 & .00000 & 93.000 & 5.0000 \\
\hline Number of Lost Customers 100 & .00000 & (Insuf) & .00000 & .00000 & .00000 \\
\hline Inventory over Time & 72.710 & 4.9792 & 18.000 & 119.00 & 85.000 \\
\hline Entity 1. WIP & 98.067 & (Corr) & 61.000 & 132.00 & 105.00 \\
\hline Remanufacturing Equipment. Number & Busy. 91703 & (Insuf) & .00000 & 1.0000 & 1.0000 \\
\hline Remanufacturing Equipment.Number & Scheduled & 1.0000 (Insi & uf) 1.0000 & 1.0000 & 1.0000 \\
\hline Remanufacturing Equipment.Utiliz & ation .9170 & 03 (Insuf) & .00000 & 1.0000 & 1.0000 \\
\hline Remanufacture.Queue. NumberInQueu & e 10.404 & (Insuf) & .00000 & 28.000 & 16.000 \\
\hline & OUTPU & UTS & & & \\
\hline Identifier & & Value & & & \\
\hline Remanufacture Number Out & & 103.00 & & & \\
\hline Transportation Accum VA Time & & $2.8524 \mathrm{E}+05$ & & & \\
\hline Remanufacture Number In & & 91.000 & & & \\
\hline Remanufacture Accum Wait Time & & 90291. & & & \\
\hline Remanufacture Accum VA Time & & 7416.0 & & & \\
\hline Transportation Number Out & & 2384.0 & & & \\
\hline Transportation Number In & & 2381.0 & & & \\
\hline Product with Customer Number Out & & 2629.0 & & & \\
\hline Product with Customer Number In & & 2654.0 & & & \\
\hline Product with Customer Accum VA T & ime & $4.1083 E+05$ & & & \\
\hline Entity 1.NumberIn & & 5308.0 & & & \\
\hline Entity 1. NumberOut & & 5298.0 & & & \\
\hline Remanufacturing Equipment. Number & Seized & 103.00 & & & \\
\hline Remanufacturing Equipment.Schedu & ledUtiliza & .91703 & & & \\
\hline System. NumberOut & & 5298.0 & & & \\
\hline
\end{tabular}


FREQUENCIES

Standard Restricted

--Occurrences--

Identifier

Percent Percent

Category

Number AvgTime

Remanufactured 100

100.00

OUT OF RANGE

1

8040.0 


\section{Appendix II}

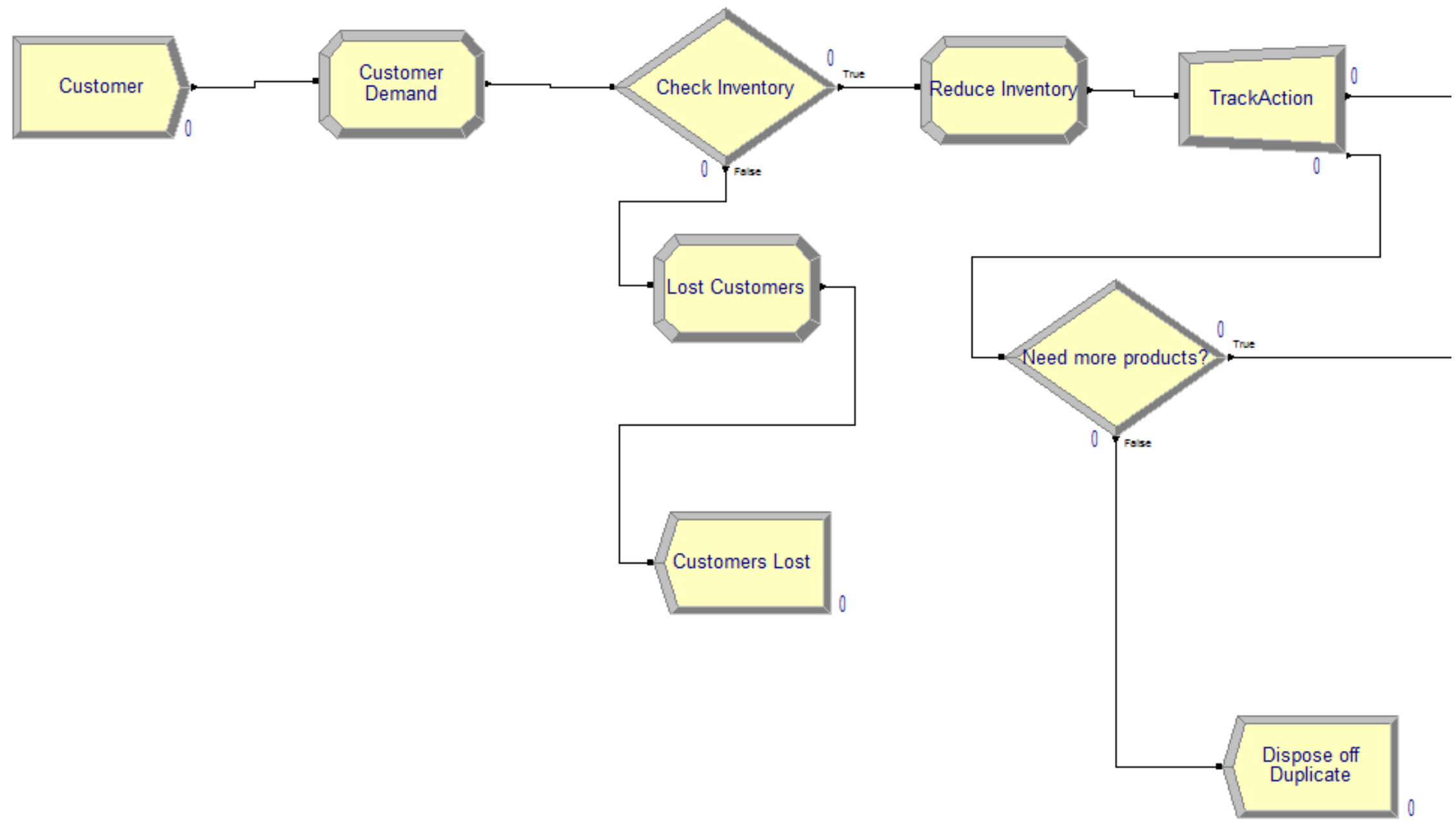




\section{Appendix II, Cont.}

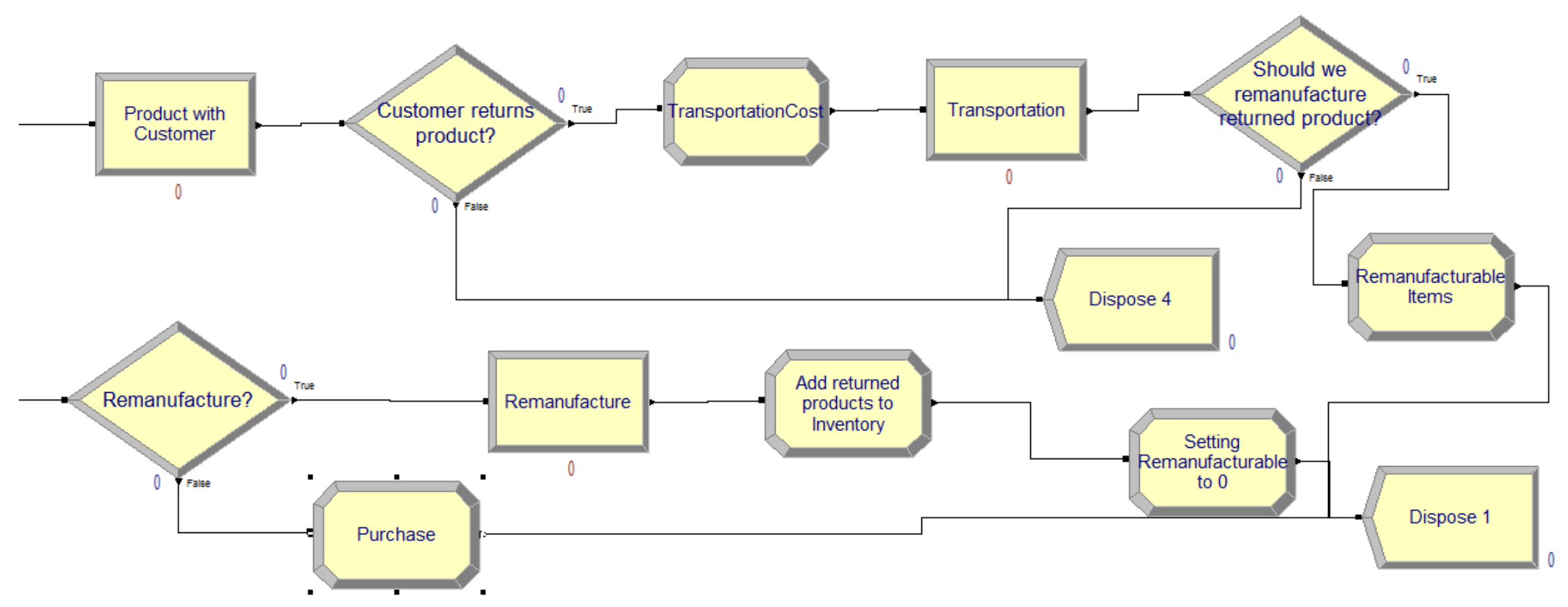




\section{Bibliography}

[1] M. Thierry, M. Salomon, J. Vannunen and L. Wassenhove, "Strategic issues in product recovery management," California Management Review37(2), p. 114-135, 1995.

[2] P. Macedo, A. Moreno, D. Alem, M. Santos and L. Junior, "Hybrid manufacturing and remanufacturing lot-sizing problem with stochastic demand, return, and setup costs," Int J Adv Manuf Technol 82, p. 1241-1257, 2016.

[3] S. Sebnem Ahiska and R. King, "Life cycle inventory policy characterizations for a single-product recoverable system,," Int.J.Production Economics, p. 51-61, 2009.

[4] S. Chopra and P. Meindl, Supply chain management strategy, planning, and operation (3rd ed.), 2007.

[5] S. Dowlatshahi, "The role of transportation in the design and implementation of reverse logistics systems," International Journal of Production Research, vol. 48, no. 14, pp. 4199-4215, 2010.

[6] R. Grubbstr"om, "Transformmethodologyappliedtosomeinventory," Zeitschrift fur Betriebswirtschaft, vol. 77, no. 3, pp. 297-324, 2007.

[7] H. Zolfaghari, M. Hafezi, R. Zanjirani Farahani and B. Fahiminia, A hybrid two-stock inventory control model for a reverse supply, Waterloo, Ontario: Transportation Research Part E, 2014.

[8] J. Shi, G. Zhang and J. Sha, "Optimal production planning for a multi-product closed loop system with uncertain demand and return," Computers \& Operations Research, vol. 38, no. 3, pp. 641-650, 2011.

[9] J. Kenné, P. Dejax and A. Gharbi, "Production planning of a hybrid manufacturing-remanufacturing system under uncertainty within a closed-loop supply chain," International Journal of Production Economics, vol. 135, no. 1, pp. 81-93, 2012.

[10] K. Govindan and M. Popiuc, "Reverse supply chain coordination by revenue sharing contract: A case for the personal computers industry," European Journal of Operational Research, vol. 233, no. 2, pp. 326-336, 2014.

[11] A. Alinovi, E. Bottani and R. Montanari, "Reverse Logistics: a stochastic EOQ-based inventory control model for mixed manufacturing/remanufacturing systems with return policies," International Journal of Production Research, vol. 50, no. 5, pp. 1243-1264, 2012.

[12] A. Jindal, K. Sangwan and S. Saxena, "Network Design and Optimization for Multi-product, Multi-time," Multi-echelon Closedloop Supply Chain under Uncertainty. Procedia CIRP, vol. 29, pp. 656-661, 2015.

[13] S. A. S and K. R, "Life cycle inventory policy characterizations for a single-product recoverable system,," Int.J.Production Economics, p. 51-61, 2009.

[14] S. Cardoso, A. Barbosa-Póvoa and S. Relvas, "Design and planning of supply chains with integration of reverse logistics activities under demand uncertainty.," European Journal of Operational Research, vol. 226, no. 3, pp. 436-451, 2013.

[15] E. Benedito and A. Corominas, "Optimal manufacturing policy in a reverse logistic system with dependent stochastic returns and limited capacities," International Journal of Production Research, vol. 51, no. 1, pp. 189-201, 2012.

[16] G. Heisig and M. Fleischmann, "Planning stability in a product recovery system," OR Spektrum, no. 23, p. 25-50, 2001.

[17] M. Fleischmann, R. Kuik and R. Dekker, "Controlling inventories with stochastic item returns: A basic model," European Journal of Operational Research, vol. 138, no. 1, pp. 63-75, 2002.

[18] C. Hsueh, " An inventory control model with consideration of remanufacturing and product life cycle," International Journal of Production Economics, vol. 133, no. 2, pp. 645-652, 2011.

[19] S. Amin and G. Zhang, "An integrated model for closed-loop supply chain configuration and supplier selection: Multi-objective approach," Expert Systems with Applications, vol. 39, no. 8, pp. 6782-6791, 2012.

[20] D. Kannan, A. Diabat, M. Alrefaei, K. Govindan and G. Yong, "A carbon footprint based reverse logistics network design model," Resour. Conserv. Recycl, vol. 67, p. Resour. Conserv. Recycl, 2012.

[21] M. Fonseca, García-Sánchezá, M. Ortega-Mier and F. Saldanha-da-Gama, "Astochastic biobjective location model for strategic reverse logistics," TOP, vol. 18, no. 1, pp. 158-184, 2010.

[22] M. Chen and P. Abrishami, "A mathematical model for production planning in hybrid manufacturing-remanufacturing systems," The International Journal of Advanced Manufacturing Technology, vol. 71, no. 5-8, pp. 1187-1196, 2014.

[23] S. Kara, F. Rugrungruang and H. Kaebernick, Simulation modelling of reverse logistics networks, Sydney , Australia: International Journal of Production Economics, March 2007, pp. 61-69.

[24] R. Russell and B. Taylor, Operations Management, New Jersey, USA: Prentice and Hall, 2003.

[25] D. Hellström and O. Johansson, "The impact of control strategies on the management of returnable transport items," Transp. Res., vol. 46, no. 6, pp. 1128-1139, 2010.

[26] D. Brito, "Reverse logistics: a review of case studies," Econometric Institute Report, vol. 21, pp. 1-32, 2002. 
[27] M. Pishvaee, M. Rabbani and S. Torabi, "A robust optimization approach to closed-loop supply chain network design under uncertainty," Appl. Math. Modell, vol. 35, no. 2, pp. 637-649, 2011.

[28] C. Achillas, D. Aidonis, C. Vlachokostas, N. Moussiopoulos, G. Banias and D. Triantafillou, "A multi-objective decision-making model to select waste electrical and electronic equipment transportation media," Resour. Conserv. Recycl, vol. 66, pp. 76-84, 2012.

[29] F. Du and G. Evans, "A bi-objective reverse logistics network analysis for post-sale service," Comput. Oper. Res, vol. 35, no. 8, p. 2617-2634, 2008.

[30] M. R. Galbreth and J. D. Blackburn, "Optimal acquisition quantities in remanufacturing with condition uncertainty," Production and Operations Management, vol. 19, p. 61-69, 2010.

[31] M. Benfield, "Appliance Recycling Project: Pilot Disassembly," Reported by Email Major http://www.ecorecycle.vic.gov.au, 2000. 